\title{
Gas Sensing Potential of Strontia Doped Yttria Stabilized Zirconia
}

\author{
Rucha R. Purandare ${ }^{1}$, Manisha Y. Khaladkar ${ }^{2}$ \\ ${ }^{1,2}$ Department of Applied Science, \\ College of Engineering Pune, \\ Shivaji Nagar, Pune-411005, \\ Maharashtra, India \\ 12abhirucha@gmail.com \\ ${ }^{2}$ myk.appsci@coep.ac.in
}

\begin{abstract}
Different samples of strontia doped yttria stabilized zirconia were synthesized by decomposition of mechanical mixture of oxalate precursors. Strontia was doped in 5 and 8 mol percent keeping yttria constant at 5 mole percent and remaining zirconia in the stoichiometry. Thermal decomposition was studied using TG and DTA from ambient to $1300^{\circ} \mathrm{C}$. In another experiment, oxalate mixtures under study were heated from ambient temperature to $1300^{\circ} \mathrm{C}$ at the rate of $10^{\circ} \mathrm{C} / \mathrm{min}$. The detailed study on phase formation temperature were carried out by heating samples from 1000 to $1300^{\circ} \mathrm{C}$ and cooling the products to room temperature and recording $X$-ray Diffraction pattern for the in process sample. Surface morphology was studied by scanning electron microscopy. The product formed was pressed into round discs and checked for its potential for sensing various gases like $\mathrm{NO}, \mathrm{H}_{2} \mathrm{~S}$ and acetone and responses were monitored at room temperature. The concentrations of the test gases used were in the range of 5-25 ppm.
\end{abstract}

Keyword- YSZ; strontia doped; phase formation; gas sensing

\section{INTRODUCTION}

Yttria stabilized zirconia( YSZ) is a widely studied ceramic compound. A lot of research work has been reported on stabilization of zirconia in partially stabilized and completely stabilized tetragonal and cubic structure. Zirconia exhibits three polymorphic forms viz. monoclinic, tetragonal and cubic. The monoclinic form of zirconia is stable at room temperature and changes to a denser tetragonal form at $1000^{\circ} \mathrm{C}$ [1]. There are disadvantages of using zirconia in monoclinic structure since it involves a volume change of about $4-5 \%$ during its conversion to tetragonal form resulting in to cracks in the structure [2]. Hence stabilization of zirconia is necessary in cubic or tetragonal form. Different cations have been used for stabilization of zirconia. This stabilization of zirconia makes it possible to be used in a wide range of applications. Amongst a variety of cations tried yttria in 8 to 15 mole percent, appears to be most advantageous and is a commercially available product for a wide range of applications [3].

Yttria stabilized zirconia also find varied applications in fields like thermal barrier coatings [4], dental ceramics [5], solid oxide fuel cells and gas sensors [6]. YSZ can be synthesized by co-precipitation, sol-gel, solid state and hydrothermal routes. YSZ has been prepared using different precursors mainly oxalate, hydroxide and citrate [7-10]. There are very few reports on partial substitution of strontium +2 ions in YSZ [11].

In present paper, synthesis of strontia doped yttria stabilized zirconia was carried out by mechanical mixing of oxalate salts. Characterisation of the resultant products was done by thermo-gravimetric analysis (TGA), differential thermal analysis (DTA), X-ray diffraction (XRD) and Scanning electron microscopy (SEM). The present paper reports the gas sensing potential of the final products with nominal composition $\left(\mathrm{Zr}_{0.90} \mathrm{Y}_{0.05} \mathrm{Sr}_{0.05}\right)$ $\mathrm{O}_{1.925} \mathrm{ZYS}-5$ and $\left(\mathrm{Zr}_{0.87} \mathrm{Y}_{0.05} \mathrm{Sr}_{0.08}\right) \mathrm{O}_{1.895} \mathrm{ZYS}-8$. Thermal profiling of the end products from 1000 to $1300^{\circ} \mathrm{C}$ was carried out to determine the phase formation temperature.

\section{EXPERIMENTAL}

\section{A. Materials}

Raw materials used: Zirconyl oxychloride octahydrate (99.9\%), yttrium nitrate tetrahydrate, strontium nitrate anhydrous, potassium oxalate monohydrate. All the raw materials used were of Fisher Scientific make and were $99.9 \%$ pure. 


\section{B. Method}

Strontia doped yttria stabilized zirconia was synthesized in two different mole proportions viz.5 and 8 by decomposition of mechanical mixture of oxalate precursors. Zirconium oxalate, yttrium oxalate and strontium oxalate were synthesized separately and then added in required stoichiometry. Zirconium oxalate was synthesized by adding zirconyl oxychloride octahydrate solution drop wise into bath of potassium oxalate monohydrate. The solution was churned for two hours, filtered, washed and dried. In similar manner, yttrium oxalate and strontium oxalate were synthesized using yttrium nitrate tetrahydrate and strontium nitrate anhydrous respectively. The oxalate salts of zirconium, yttrium and strontium were mixed in required stoichiometry and were ball milled for two hours. The oxalate mixtures were heated in alumina boats from room temperature to $1100^{\circ} \mathrm{C}$. The compositions $\left(\mathrm{Zr}_{0.90} \mathrm{Y}_{0.05} \mathrm{Sr}_{0.05}\right) \mathrm{O}_{1.925}$ and $\left(\mathrm{Zr}_{0.87} \mathrm{Y}_{0.05} \mathrm{Sr}_{0.08}\right) \mathrm{O}_{1.895}$ will now be abbreviated as ZYS-5 and ZYS-8 respectively.

The raw, ball milled mixture was subjected to simultaneous TG/DTA from ambient to $1300^{\circ} \mathrm{C}$. The ball milled mixtures of ZYS-5 and ZYS-8 were then calcined at $1000^{\circ} \mathrm{C}, 1100^{\circ} \mathrm{C}, 1200^{\circ} \mathrm{C}$ and $1300^{\circ} \mathrm{C}$ for two hours each in a temperature programmed furnace. The samples were cooled to room temperature and then subjected to X-ray Diffractometry (XRD) and scanning electron microscopy (SEM) to study the phase formation temperature and surface morphology respectively.

\section{Instrumentation}

Thermal analyses of the samples were carried out in an in house fabricated TG instrument. The powder samples were tested by X-ray diffractometer (Model: Bruker D8 Advance) for the crystal structure and morphology was studied by Scanning Electron Microscope (Model: JEOL JSM 6360A) for surface morphology. The gas sensing was carried out in a fabricated glass assembly using Keithley 61/2-Digit Dual Display Digital Multimeter Model 2000. The pelletized samples were placed in the fabricated assembly and was exposed to different gases namely hydrogen sulphide $\left(\mathrm{H}_{2} \mathrm{~S}\right)$, nitric oxide $(\mathrm{NO})$ and acetone vapours with the help of a syringe (Hamilton syringes). Change in resistance was measured using digital multimeter. The gases $\mathrm{H}_{2} \mathrm{~S}$ and NO were procured from Alchemie Gases Pvt Ltd, Mumbai and had 99.5\% purity. Acetone used for sensing was procured from Fisher Scientific (AR grade).

\section{RESULTS AND DISCUSSION}

\section{A. Thermal Analysis}

The exothermic oxalate decomposition is expected to catalyze the decomposition of individual oxalates and hence the ternary metal oxide with composition $\left(\mathrm{Zr}_{0.90} \mathrm{Y}_{0.05} \mathrm{Sr}_{0.05}\right) \mathrm{O}_{1.925}$ forms at temperature around 1100$1200^{\circ} \mathrm{C}$. In our earlier work on binary and ternary oxalate mixtures [12],[13], similar type of effect has reduced the phase formation temperature by more than $250^{\circ} \mathrm{C}$. Such reduced decomposition temperature presents advantage that in just decomposed state the cations formed are more active, hence single phase product formation occurs. Also, contamination or secondary binary phase formation is reduced. The product formed will be more homogeneous and uniform in particle size. Table 1 shows the details of weight loss occured in different steps and the species lost in each step.

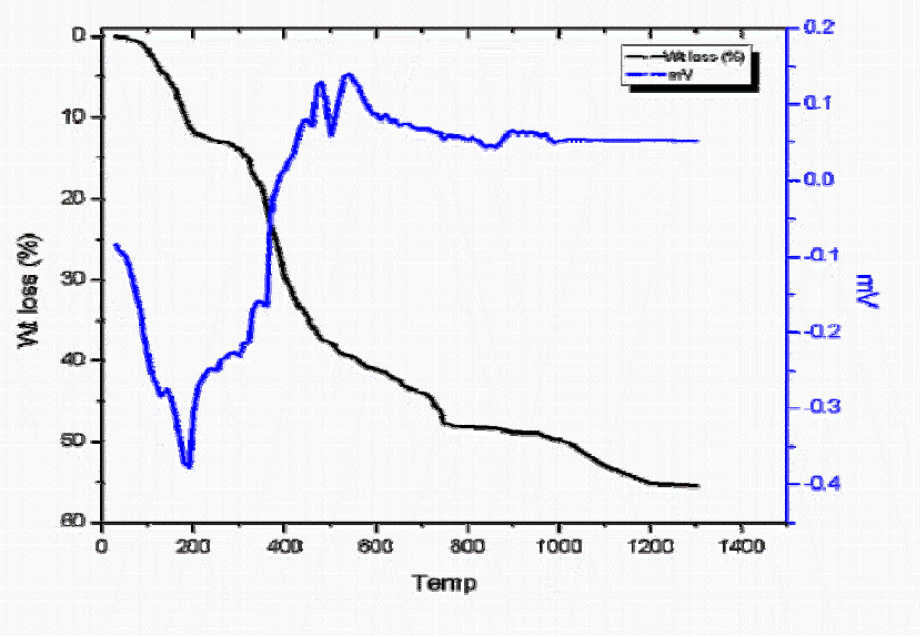

Fig. 1. TG/DTA plot of ZYS-5 
Table I. TG Analysis of ZYS-5

\begin{tabular}{|c|c|c|c|}
\hline Steps & Temperature $\left({ }^{\circ} \mathbf{C}\right)$ range & \% weight loss & Species lost \\
\hline 1 & RT to 100 & & Adsorbed moisture \\
\hline 2 & 101 to 230 & 11.71 & $2 \mathrm{H}_{2} \mathrm{O}$ \\
\hline 3 & 231 to 950 & 37.28 & $1 \mathrm{CO}, 2 \mathrm{CO}_{2}$ \\
\hline 4 & 951 to 1300 & 55.47 & $1 \mathrm{CO}$ \\
\hline
\end{tabular}

Thermal decomposition of ZYS-8 is shown below in fig. 2

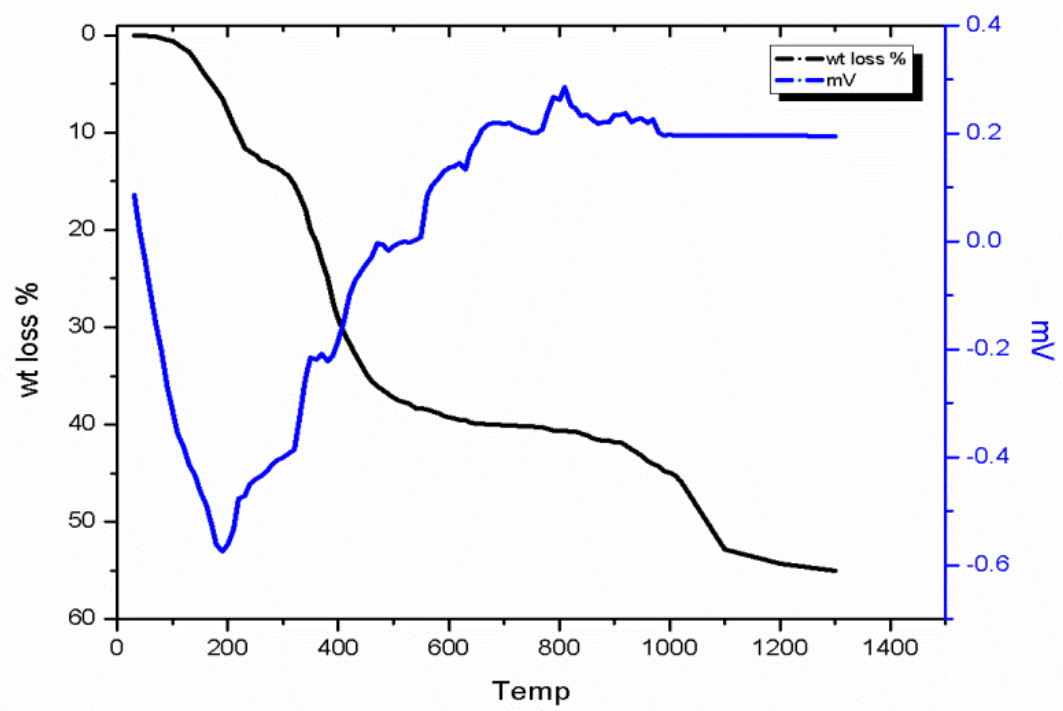

Fig. 2. TG/DTA plot of ZYS-8

The decomposition sequence with stepwise weight loss and species lost is summarised below

Table II. TG Analysis of ZYS-8

\begin{tabular}{|c|c|c|c|}
\hline Steps & Temperature $\left({ }^{\circ} \mathbf{C}\right)$ range & \% weight loss & Species lost \\
\hline 1 & RT to 110 & & $\begin{array}{c}\text { Adsorbed } \\
\text { moisture }\end{array}$ \\
\hline 2 & 111 to 230 & 10.63 & $1.75 \mathrm{H}_{2} \mathrm{O}$ \\
\hline 3 & 231 to 890 & 31.31 & $2 \mathrm{CO}+0.75 \mathrm{CO}_{2}$ \\
\hline 4 & 891 to 1300 & 55.02 & $0.8 \mathrm{CO}_{2}$ \\
\hline
\end{tabular}




\section{B. XRD study}

ZYS-5 heated from $1000-1300^{\circ} \mathrm{C}$ at an interval of $100 \mathrm{C}$ is shown below in Fig. 3a

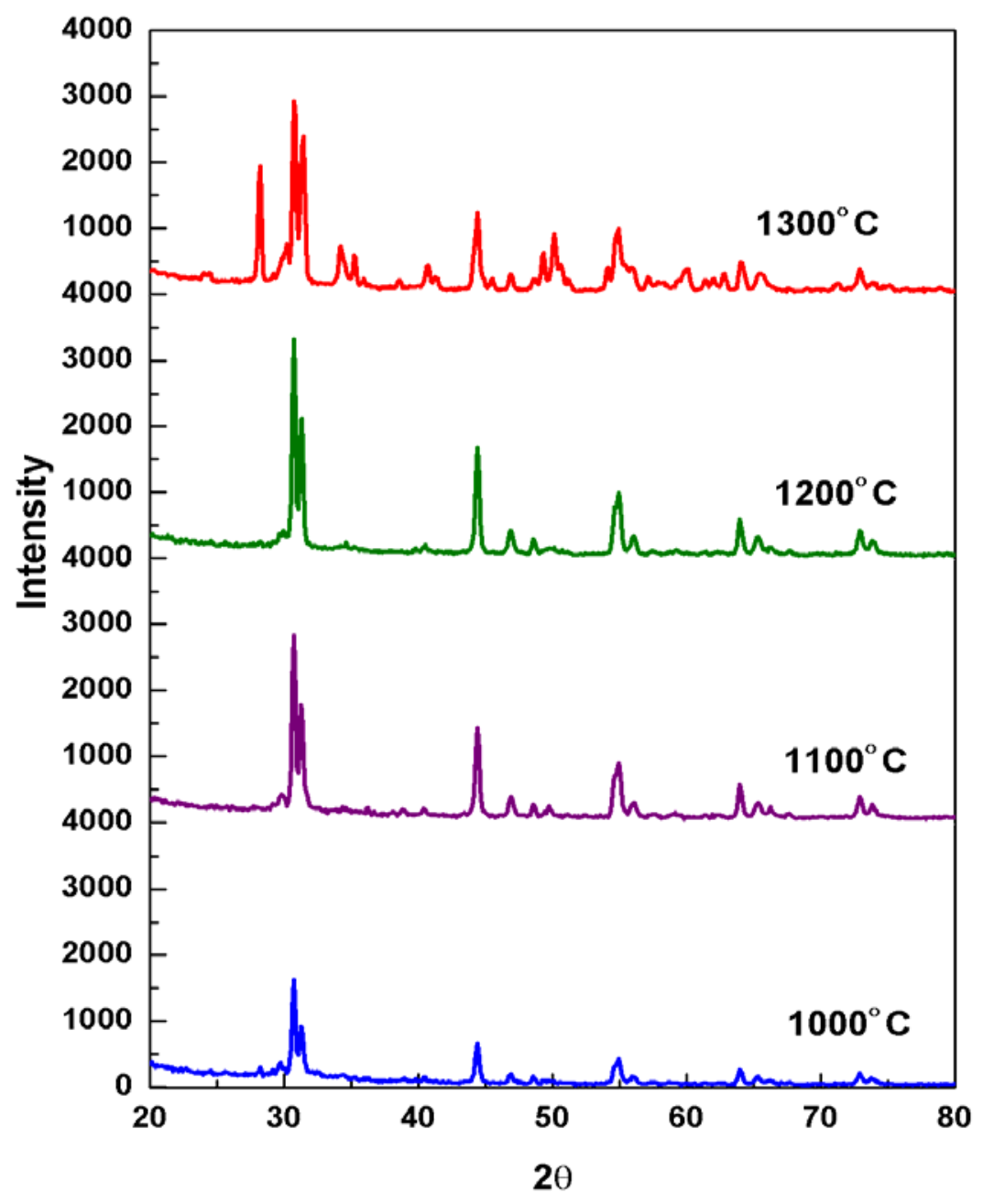

Fig.3a. XRD of ZYS-5 calcined at different temperature

From the diffraction pattern of ZYS-5 (Fig.3a), it can be observed that the phase starts forming at around $1100^{\circ} \mathrm{C}$ and is complete at $1200^{\circ} \mathrm{C}$. Above this temperature the disintegration of the phase begins, which can be seen from the XRD pattern at $1300^{\circ} \mathrm{C}$. The $100 \%$ peak starts disintegrating at around $1300^{\circ} \mathrm{C}$. Major peaks are observed at $30.7^{\circ}, 44.4^{\circ}$ and $54.9^{\circ}$ which are characteristic of cubic perovskite structure.

Fig $3 b$, shows XRD patterns recorded for ZYS-8 heated at 1000, 1100, 1200 and $1300^{\circ} \mathrm{C}$. 


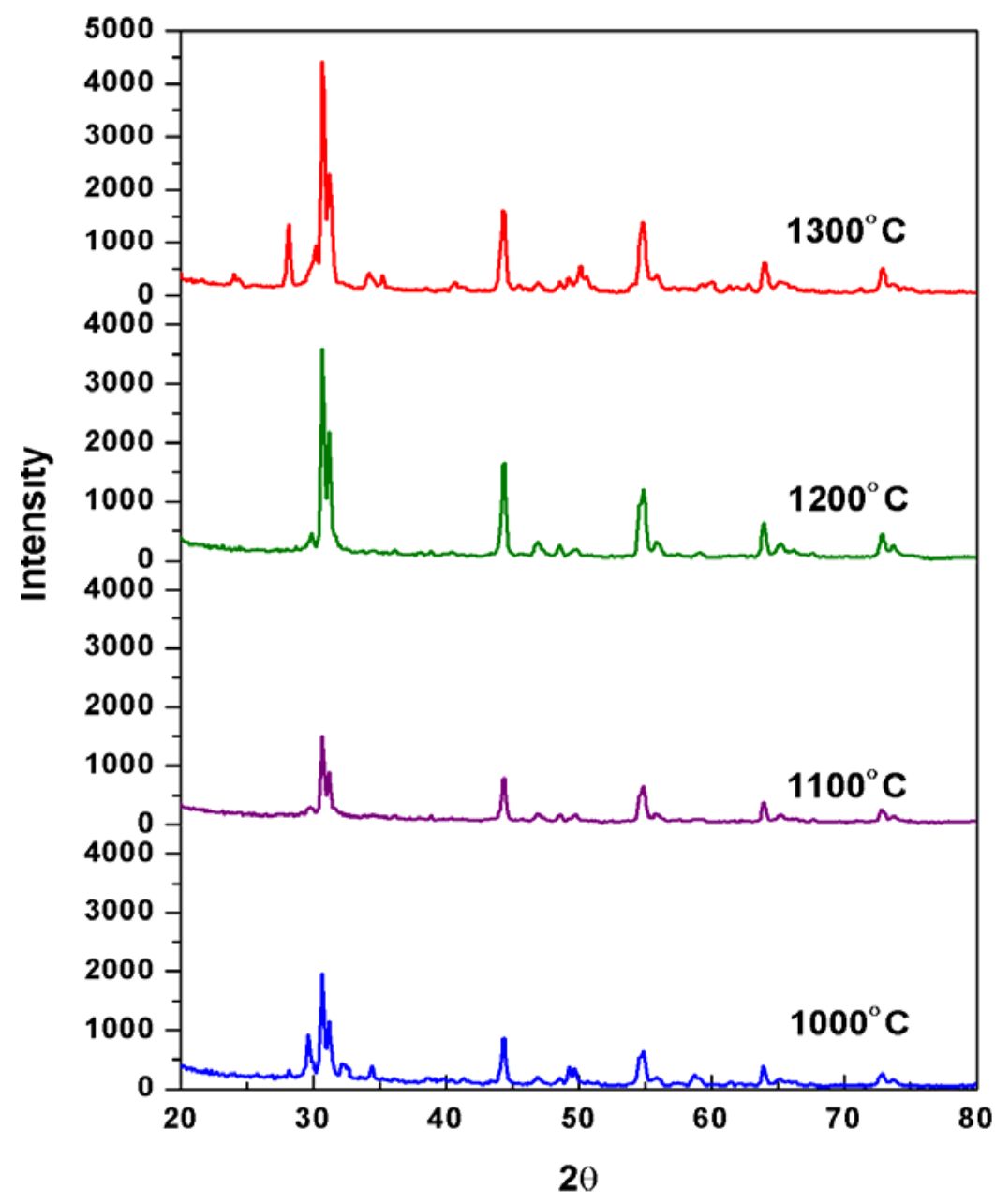

Fig.3b. XRD of ZYS-8 calcined at different temperatures

Similar is the case with ZYS- 8 (Fig. $3 \mathrm{~b}$ ) in which phase is seen to be disintegrated at $1300^{\circ} \mathrm{C}$. On calcination at $1000^{\circ} \mathrm{C}$, the crystalinity is poor. A sample heated upto 1100 shows improved crystallinity. Whereas, after heating till $1200^{\circ} \mathrm{C}$, the crystal structure is well grown and the peaks are distinct. After heating till $1300^{\circ} \mathrm{C}$, there is splitting of peak observed at 2 theta 30.7 and a small peak is seen at 28 which was absent at lower temperatures. The peaks are broadened and the phase seems to be disintegrated. In all above XRD patterns the $100 \%$ peak appears at $30.7^{\circ}$ confirming formation of cubic perovskite phase.

The average crystallite sizes of both the samples calcined at different temperatures from $1000^{\circ} \mathrm{C}$ to $1300^{\circ} \mathrm{C}$ were calculated (Table III). From the values it was observed that the average crystallite size in ZYS-5 as well as ZYS-8 is highest after calcination at $1200^{\circ} \mathrm{C}$. After heating at $1300^{\circ} \mathrm{C}$, it was observed that the particle size decreased. Hence it can be concluded that the calcination temperature should be $1200^{\circ} \mathrm{C}$.

Table III. Average Crystallite Sizes of ZYS-5 and ZYS-8

\begin{tabular}{|l|c|c|c|c|}
\hline \multirow{2}{*}{ Samples } & \multicolumn{4}{|c|}{ Average crystallite sizes at different temperatures } \\
\cline { 2 - 5 } & $1000{ }^{\circ} \mathrm{C}$ & $1100^{\circ} \mathrm{C}$ & $1200^{\circ} \mathrm{C}$ & $1300^{\circ} \mathrm{C}$ \\
\hline ZYS-5 & 19.84 & 20.03 & $\mathbf{2 0 . 6 6}$ & 18.66 \\
\hline ZYS-8 & 21.41 & 21.55 & $\mathbf{2 3 . 8 3}$ & 23.54 \\
\hline
\end{tabular}




\section{SEM study}

Sintered pellets of ZYS-5 and ZYS-8 heated at1000, 1100,1200 and $1300^{\circ} \mathrm{C}$ was used for SEM studies. The images obtained are shown below in Fig 4a and b.
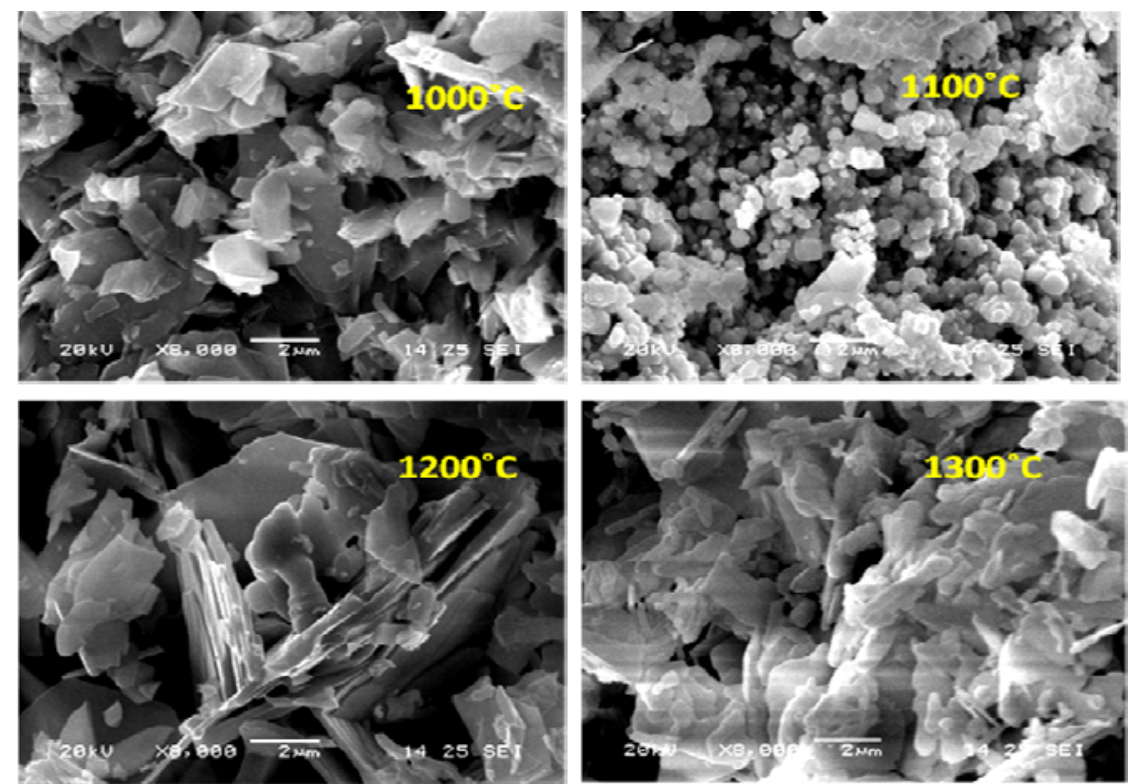

Fig. 4a. SEM micrographs of ZYS-5 calcined at different temperatures

In ZYS-5 (Fig.4a), sample heated at $1200^{\circ} \mathrm{C}$ shows highest particle size, more regularity, more translucence and more glassy structure amongst all temperature from $1000-1300^{\circ} \mathrm{C}$. At $1100^{\circ} \mathrm{C}$, the structure appears to be in transition from $1000-1100^{\circ} \mathrm{C}$ and 1100 to $1200^{\circ} \mathrm{C}$. Therefore, for calcination and sintering, ideal temperature should be $1200^{\circ} \mathrm{C}$. The structure transforms from fine laminar flakes to nano particles to fused laminar sheets and at $1300^{\circ} \mathrm{C}$ on top of the sheets there are depositions of smaller particles.
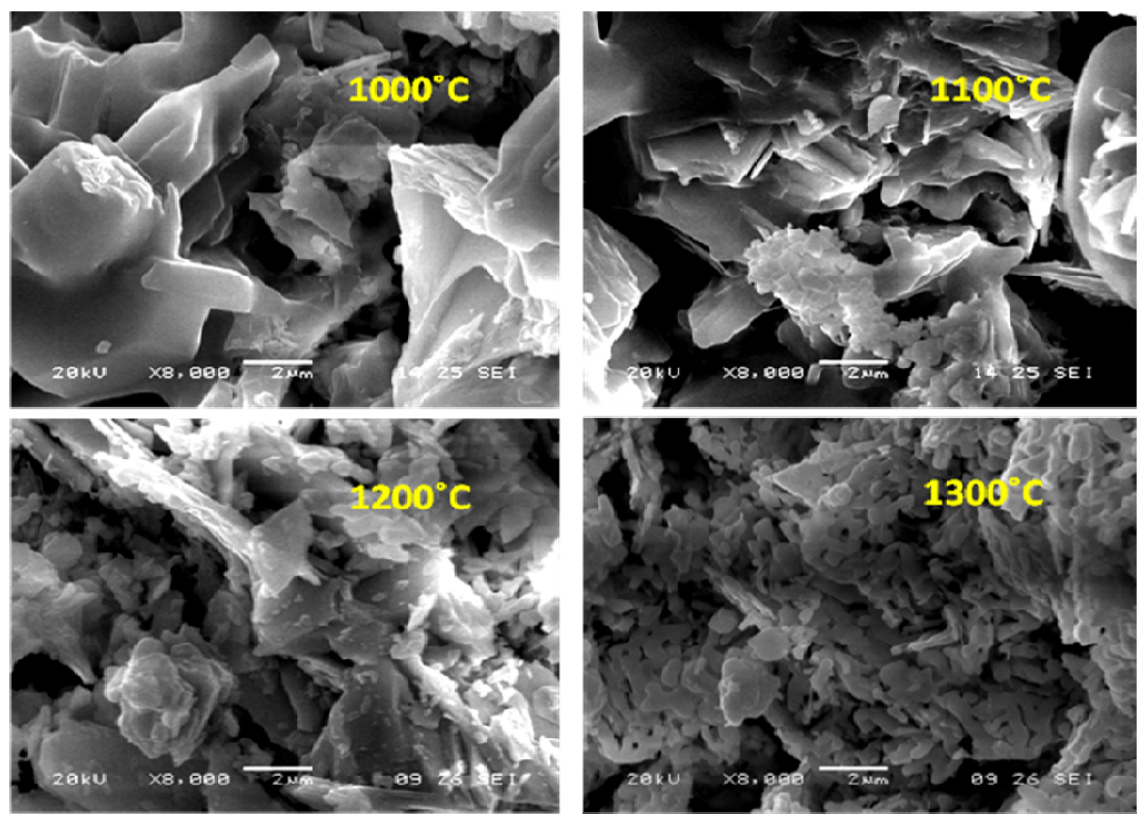

Fig.4b. SEM micrographs of ZYS-8 calcined at different temperatures

For ZYS-8 (Fig. 4 b), at $1000^{\circ} \mathrm{C}$ the glassy, laminar particles are formed which on further heating disintegrate into broken, smaller particles with reduction in density. Hence for ZYS-8, heating should not go beyond 1100 to $1150^{\circ} \mathrm{C}$. Samples heated at $1200^{\circ} \mathrm{C}$ or $1300^{\circ} \mathrm{C}$ show charging effect as well and particle size decreases from 5 microns to a fraction of micron. 
The average particle size appears to be maximum in ZYS-8 composition. With the increase in strontium percentage, there is destruction of the phase. Hence, uniformity in particle size, laminar structure and glass appearance reduces from 5 to $8 \mathrm{~mol} \%$ of $\mathrm{Sr}$.

\section{Sensing study}

The pellets with nominal composition $\left(\mathrm{Zr}_{0.90} \mathrm{Y}_{0.05} \mathrm{Sr}_{0.05}\right) \mathrm{O}_{1.925}$ and $\left(\mathrm{Zr}_{0.87} \mathrm{Y}_{0.05} \mathrm{Sr}_{0.08}\right) \mathrm{O}_{1.895}$ were used for measurement of gas sensing ability. The pellets were kept in an in-house fabricated glass assembly and were further connected to digital multimeter.

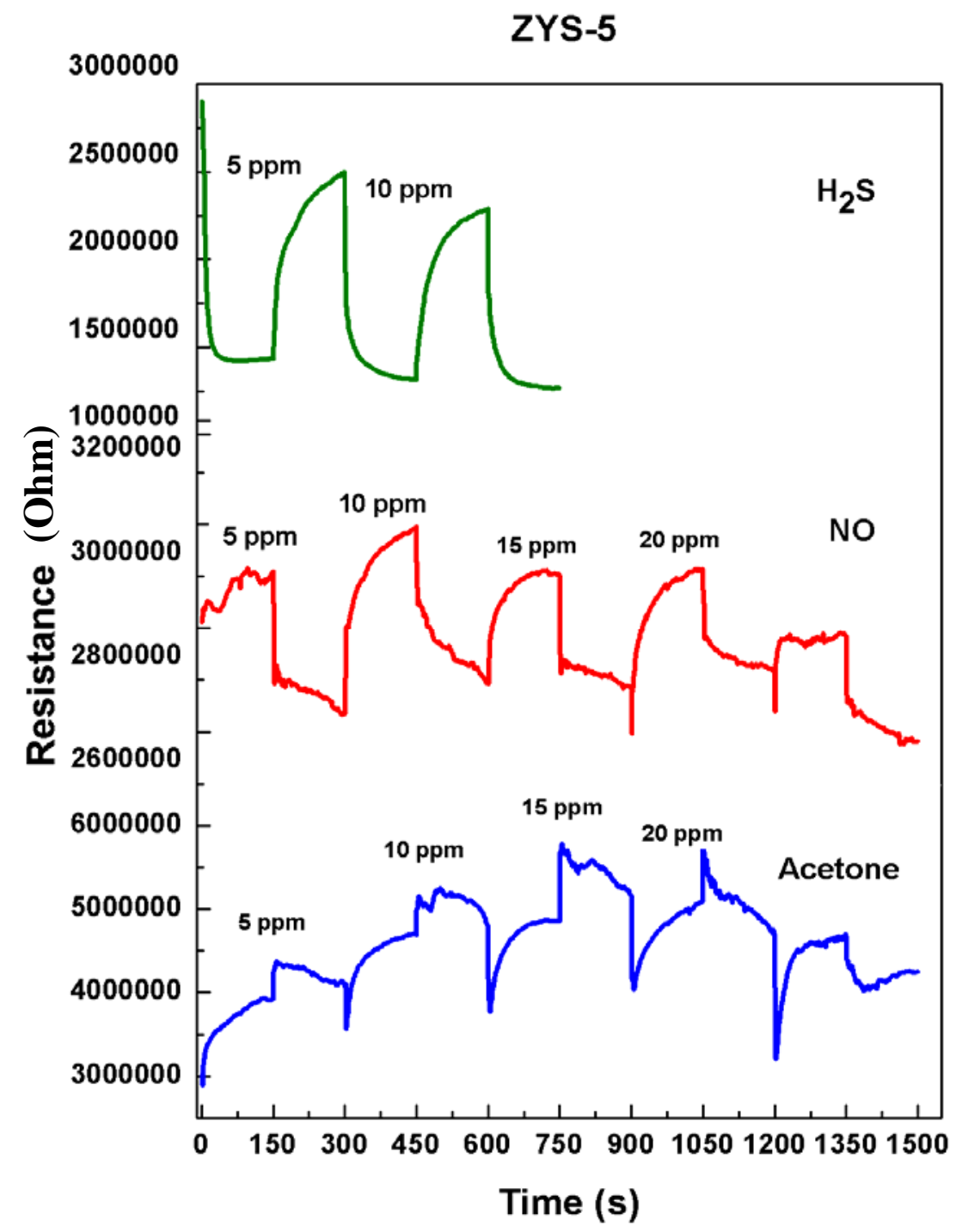

Fig. 5a. Sensing graphs of ZYS-5

It appears that ZYS-5 (Fig. 5a) shows higher sensitivity towards reducing gases like $\mathrm{H}_{2} \mathrm{~S}$ and NO. Saturation level for NO is around $20 \mathrm{ppm}$ and shows excellent sensitivity in the range of 5 to $20 \mathrm{ppm}$. It is highly reproducible and at room temperature, desorption time is as low as $50 \mathrm{sec}$. ZYS-5 shows sensitivity for $\mathrm{H}_{2} \mathrm{~S}$ at around $10 \mathrm{ppm}$. The saturation level for $\mathrm{H}_{2} \mathrm{~S}$ is around $15 \mathrm{ppm}$. In case of acetone, the result is not reproducible beyond $10 \mathrm{ppm}$. 


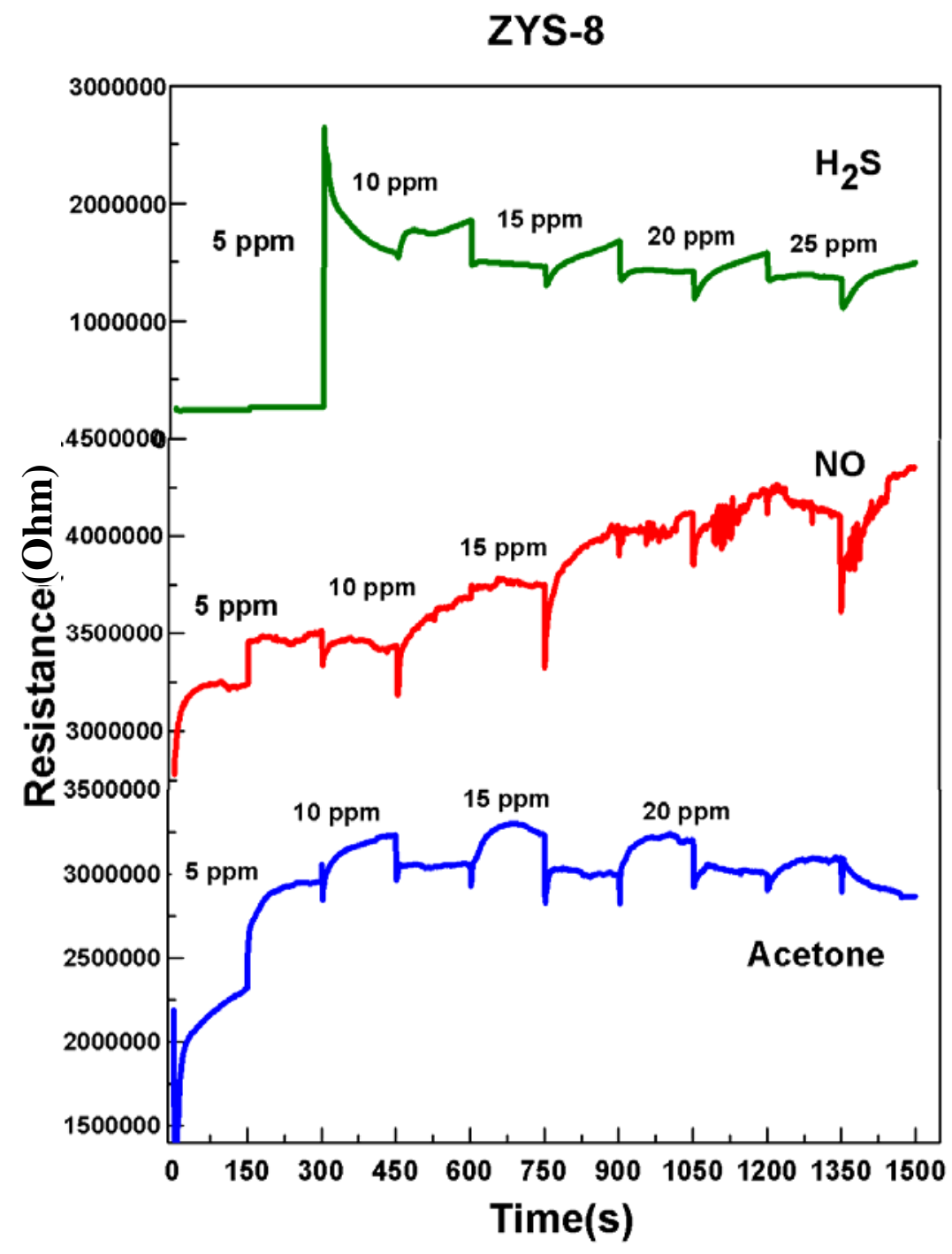

Fig. 5b: Sensing graphs of ZYS-8

ZYS-8 (Fig.5b) shows poor sensitivity towards NO and acetone but shows better sensitivity even at lower concentrations of $\mathrm{H}_{2} \mathrm{~S}$. Both ZYS-5 and ZYS-8 can be used as in-line process equipment if there is in-situ generation of $\mathrm{H}_{2} \mathrm{~S}$ during manufacturing operations.

\section{CONCLUSIONS AND FUTURE SCOPE}

- Oxalate mechanical mixtures are good precursors for synthesis of ZYS-5 \& ZYS-8.

- The crystal structure is Cubic perovskit

-During oxalate decomposition dehydration, loss of $\mathrm{CO}$ and loss of $\mathrm{CO} 2$ is observed in the temperature range $100-230,230-950$ and $950-1150^{\circ} \mathrm{C}$ respectively.

- Composition of the decomposition product are $\left.\mathrm{Zr}_{0.90} Y_{0.05} \mathrm{Sr}_{0.05}\right) \mathrm{O}_{1.925}$ and $\left(\mathrm{Zr}_{0.87} Y_{0.05} \mathrm{Sr}_{0.08}\right) \mathrm{O}_{1.895 .}$

-ZYS-5 shows better sensitivity towards reducing gases like $\mathrm{NO}$ and $\mathrm{H}_{2} \mathrm{~S}$ and no sensitivity towards acetone as compared to ZYS-8

\section{ACKNOWLEDGMENTS}

This work was supported by funding from ISRO-UoP-STC. The authors are also thankful to Department of Physics, University of Pune for analytical support. 


\section{REFERENCES}

[1] Behchepeche A. P.; Treu Jr. O. E.; Longo. E; Paiva-Santos. C. O.; Varela. J. A.; Experimental and theoretical aspects of the stabilization of zirconia ; Journal of Materials Science, vol.34, pp 2751 - 2756, 1999.

[2] Anup K. Bhattacharya; Patrick Reinhard; Walter Steurer; Valery Shklover; Calcia-doped yttria-stabilized zirconia for thermal barrier coatings: synthesis and characterization; Journal of Materials Science, vol. 46, pp. 5709-5714, 2011.

[3] Ahmed. T. O.; Akusu. P. O.; Jonah. S. A.; Rabiu. N; Phase Evolution in Co-Precipitated Stabilized Zirconia Powders; Physical Review \& Research International; vol. 2(2), pp. 75-90, 2012.

[4] Carlos G. Levi; Emerging materials and processes for thermal barrier systems; Current Opinion in Solid State and Materials Science, vol. 8, pp. 77-91, 2004.

[5] Yuhua Wang; Hui Huang; Limin Gao; Fuqiang Zhang; Investigation of a new 3Y-stabilized zirconia with an improved optical property for applications as a dental ceramic; Journal of Ceramic Processing Research, vol. 12 (4), pp. 473-476, 2011.

[6] Satyajit Shukla; Sudipta Seal; Rashmi Vij; Sri Bandyopadhyay; Reduced Activation Energy for Grain Growth in Nanocrystalline Yttria-Stabilized Zirconia ; Nano Letters, vol. 3 (3), pp. 397-401, 2003.

[7] Khaladkar M.Y.; Purandare R.R.; Comparative study of yttria stabilized zirconia by co-precipitation method using various precursors and its potential as gas sensor; International Journal of Research in Chemistry and Environment, vol. 6(2), pp. 14-17, 2016.

[8] K. Geethalakshmi; T. Prabhakaran; J. Hemalatha; Dielectric Studies on Nano Zirconium Dioxide Synthesized through CoPrecipitation Process; World Academy of Science, Engineering and Technology,vol. 64, pp. 179-182, 2012.

[9] Rashad M.M.; Baioumy H.M.; Effect of thermal treatment on the crystal structure and morphology of zirconia nanopowders produced by three different routes; Journal Of Materials Processing Technology, vol. 195, pp. 178-185, 2008.

[10] Srinivasan.R.; De Angelis.R.J; Ice. G.; Davis. B. H.; Identification of tetragonal and cubic structures of zirconia using synchrotron x-radiation source; Journal of Material Research, vol. 6(6), pp. 1287-1292, 1991.

[11] E. C. Lu; E. Iglesia; Synthesis of yttria-doped strontium-zirconium oxide powders via ammonium glycolate combustion methods as precursors for dense ceramic membranes ; Journal of Materials Science, vol. 36, pp. 77- 86, 2001.

[12] L. Bapat; G. N. Natu; M. Bhide; J. Kher; Reactivity of binary mixtures of Cu(II) oxalate and La(III) oxalate; Journal of Thermal Analysis, 48, 1337-1349, 1997.

[13] L. Bapat; G. N. Natu; M. Bhide; J. Kher; Reactivity of oxalates of $\mathrm{La}(\mathrm{III}), \mathrm{Ba}(\mathrm{II})$ and $\mathrm{Cu}(\mathrm{II})$ in trenary mixtures; Journal of Thermal Analysis, 48, 819-834, 1997.

\section{AUTHOR PROFILE}

Rucha Purandare is working as a project assistant at Department of Applied Science, Government College of Engineering, Pune. She received her Master's degree in Chemistry from Amravati University and M. Phil from Madurai Kamaraj University. Currently, she is pursuing her Ph.D. in Chemistry in the area of Materials Science. Her research interests include sensor materials, ceramics and solid oxide fuel cells.

Manisha Khaladkar is working as an associate professor in chemistry at Department of Applied Science, Government College of Engineering, Pune. She did her Ph.D. in Analytical Chemistry (1997) at the Department of Chemistry, University of Pune. She has 19 years of research experience and around 25 publications in the field of analytical chemistry and materials science. Her research interests include ceramics, dielectric materials and sensors. 